\title{
Atmospheric Products from the Upper Atmosphere Research Satellite (UARS)
}

\author{
Suraiya P. Ahmad, James E. Johnson, and Charles H. Jackman
}

\section{Brief, Popular Summary of the Paper:}

This paper provides information on the products available at the NASA Goddard Earth Sciences (GES) Distributed Active Archive Center (DAAC) from the Upper Atmosphere Research Satellite (UARS) mission. The GES DAAC provides measurements from the primary UARS mission, which extended from launch in September 1991 through September 2001. The ten instruments aboard UARS provide measurements of atmospheric trace gas species, dynamical variables, solar irradiance input, and particle energy flux.

All standard Level 3 UARS products from all ten instruments are offered free to the public and science user community. The Level 3 data are geophysical parameters, which have been transformed into a common format and equally spaced along the measurement trajectory. The UARS data have been reprocessed several times over the years following improvements to the processing algorithms. The UARS data offered from the GES DAAC are the latest versions of each instrument.

The UARS data may be accessed through the GES DAAC website at http://daac. gsff.nasa.gov. 


\title{
ATMOSPHERIC PRODUCTS FROM THE UPPER ATMOSPHERE RESEARCH SATELLITE (UARS)
}

\author{
Suraiya P. Ahmad ${ }^{1}$, James E. Johnson ${ }^{1}$, and Charles H. Jackman ${ }^{2}$

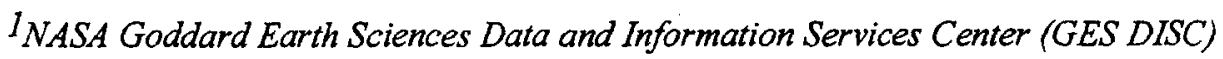 \\ Data Active Archive Center (DAAC), Code 902 \\ 2 Atmospheric Chemistry and Dymamics Branch, Code 916 \\ NASA Goddard Space Flight Center, Greenbelt, MD 20771, USA
}

\begin{abstract}
The Upper Atmosphere Research Satellite (UARS) was the first satellite to be launched under the Earth Observing System (EOS) science program of multi-mission observing systems of the National Aeronautics and Space Administrations (NASA). The EOS program was conceived to advance the understanding of the Earth-Atmosphere system on the global scale. The UARS was launched in September 1991 with ten instruments dedicated entirely to increasing understanding of the chemistry and dynamics of the Earth's stratosphere and mesosphere. After 10 years of successful data collection (far exceeding the originally projected lifetime of 3 years), the official mission ended in September 2001. However, seven instruments aboard UARS are still operational and six regularly take measurements. It is expected that the UARS will overlap the Earth Observing System (EOS) Aura satellite (to be launched in early 2004) for several months before the end of the UARS mission. The UARS data and atmospheric chemistry and dynamics data from other satellites are archived at the NASA Goddard Earth Sciences (GES) Distributed Active Archive Center (DAAC) and are available free to the public and science user community. The UARS data and related documents may be accessed through the GES DAAC website (http://daac.gsfc.nasa.gov). This paper gives an overview of the UARS products. Detailed information on UARS instruments, mission highlights and related publications are available from UARS project website (http://umpgal.gsfc.nasa.gov).
\end{abstract}

\section{INTRODUCTION}

As a major element in NASA's comprehensive Upper Atmosphere Research Program, the Upper Atmosphere Research Satellite (UARS) was launched on September 12, 1991 aboard the Space Shuttle Discovery, into a near circular orbit at an altitude of approximately $580 \mathrm{~km}$ with an inclination of 57 degrees. Ten instruments (four for measuring concentration of atmospheric trace gases, two for atmospheric dynamics variables, three for solar input irradiances, and one for energetic particle depositions) were flown aboard UARS with the goal to understand 1) the response of the upper atmospheric chemistry to natural and human perturbations, 2) the chemical processes and dynamics that control upper atmosphere structure and variability, and 3) couplings of the lower and upper atmosphere that play a major role in defining climate and climate variability.

UARS with its ten unique instruments has been providing high quality global measurements of the atmospheric parameters in the stratosphere, mesosphere, and lower thermosphere. Eleven years after launch, the UARS continues to operate and make relevant measurements. Seven of the original ten instruments aboard the UARS are still functional and six instruments regularly make measurements on a power-sharing plan. As of October 1, 2001, the UARS program started a new phase of its life called a "Traceability Mission". The schedule for UARS instrument operations has been optimized since January 2002 to be available for the validation and calibration of the future instruments aboard the new satellites. 
The UARS data are unique from previous atmospheric data collected in the sense that the 10 different instruments are able to provide simultaneous measurements of the concentration of different atmospheric trace gases (ozone, methane, water, halogens, nitrogen-containing molecules and other chemical constituents), atmospheric dynamic variables (temperature, pressure, wind fields), and measurements of the external cosmic influences acting upon the upper atmosphere (solar radiation and high energy particle depositions) on a continuing basis.

The UARS standard data products are archived at NASA Goddard Earth Sciences Data and Information Services Center (GES DISC) Distributed Active Archive Center (DAAC). UARS data and other climate data sets are provided free to the public and scientists working in major climate related disciplines such as atmospheric dynamics, atmospheric chemistry, global land and ocean biosphere, and hydrological sciences. This paper provides highlights of the climate data available from the Goddard DAAC, including data services provided by the DAAC Data Support Teams in support of the users of the data.

\section{UARS INSTRUMENTS AND DATA PRODUCTS}

The four UARS instruments that provide measurements of atmospheric trace gas species (including ozone, water vapor, methane, sulphur dioxide, carbon monoxide, chlorofluorocarbons, and many nitrogen \& chlorine compounds) from tropopause to the mesopause are:

- Cryogenic Limb Array Etalon Spectrometer (CLAES)

- Halogen Occultation Experiment (HALOE)

- Improved Stratospheric and Mesospheric Sounder (ISAMS)

- Microwave Limb Sounder (MLS)

CLAES and ISAMS also measured aerosols; these two instruments are no longer operating. In April 1993, the cryogen in CLAES expired on schedule, and due to a mechanical problem ISAMS ceased working in July 1992. At about the same time MLS lost its $183 \mathrm{GHz}$ radiometer (used for stratospheric water vapor and mesospheric ozone) but the other two radiometers (at 63 and $205 \mathrm{GHz}$ ) making constituent measurements were unaffected, however, presently the MLS instrument is in the standby mode for future use. At present, among the above four sensors HALOE is the only one which is making continuous measurements.

The two instruments that provide atmospheric dynamic variables (stratospheric and mesospheric meridional \& zonal wind fields, volume emission rate, and temperature profiles of the upper atmosphere) are:

- High Resolution Doppler Imager (HRDI)

- Wind Imaging Interferometer (WINDII)

HRDI provides coverage in the stratosphere $(10-50 \mathrm{~km})$ and in the mesosphere and lower thermosphere (MLT) region (50-115 km), while WINDII makes measurements in the mesosphere and thermosphere $(90-300 \mathrm{~km})$.

The solar irradiance input and particle energy flux entering the atmosphere are measured by the instruments:

- Solar/Stellar Irradiance Comparison Experiment (SOLSTICE)

- Solar Ultraviolet Spectral Irradiance Monitor (SUSIM)

- $\quad$ Active Cavity Radiometer Irradiance Monitor (ACRIM II)

- Particle Environment Monitor (PEM)

SOLSTICE (spectral region 115 to $420 \mathrm{~nm}$ ) and SUSIM (115 to $410 \mathrm{~nm}$ ) provide spectral solar UV irradiance at spectral resolution of $\sim 0.1 \mathrm{~nm}$. ACRIM II provides total solar irradiance. PEM provides electrons, protons, and xrays energy deposition rates, and magnetic field.

Six of the original ten instruments aboard the UARS (SOLSTICE, SUSIM, PEM, HRDI, WINDII, HALOE) regularly take measurements. Detailed description of each instrument can be found in the special issue, Journal of Geophysical Research (98(D6), 10643-10814, 1993). The overview of the mission and the highlights are reported 
by Schoeberl et al. (1994), and Jackman and Douglass (2003). A list of many of the UARS related publications by the science team and the mission status can be found from the UARS project web site http://umpgal.gsfc.nasa.gov.

The UARS data set also include two correlative data products for verifying geophysical parameters derived from the UARS instruments. Correlative data from the National Meteorological Center (NMC), now called the National Centers for Environmental Prediction (NCEP), includes assimilated data of temperature, winds ( $u$ and $v$ components), moisture, and geopotential height. The correlative data from the United Kingdom Meteorological Office (UKMO) includes temperature, meridional and zonal winds, vertical velocity (omega), and geopotential height parameters. List of the geophysical parameters retrieved from the measurements made by the UARS instruments are given below in Tables 1-3.

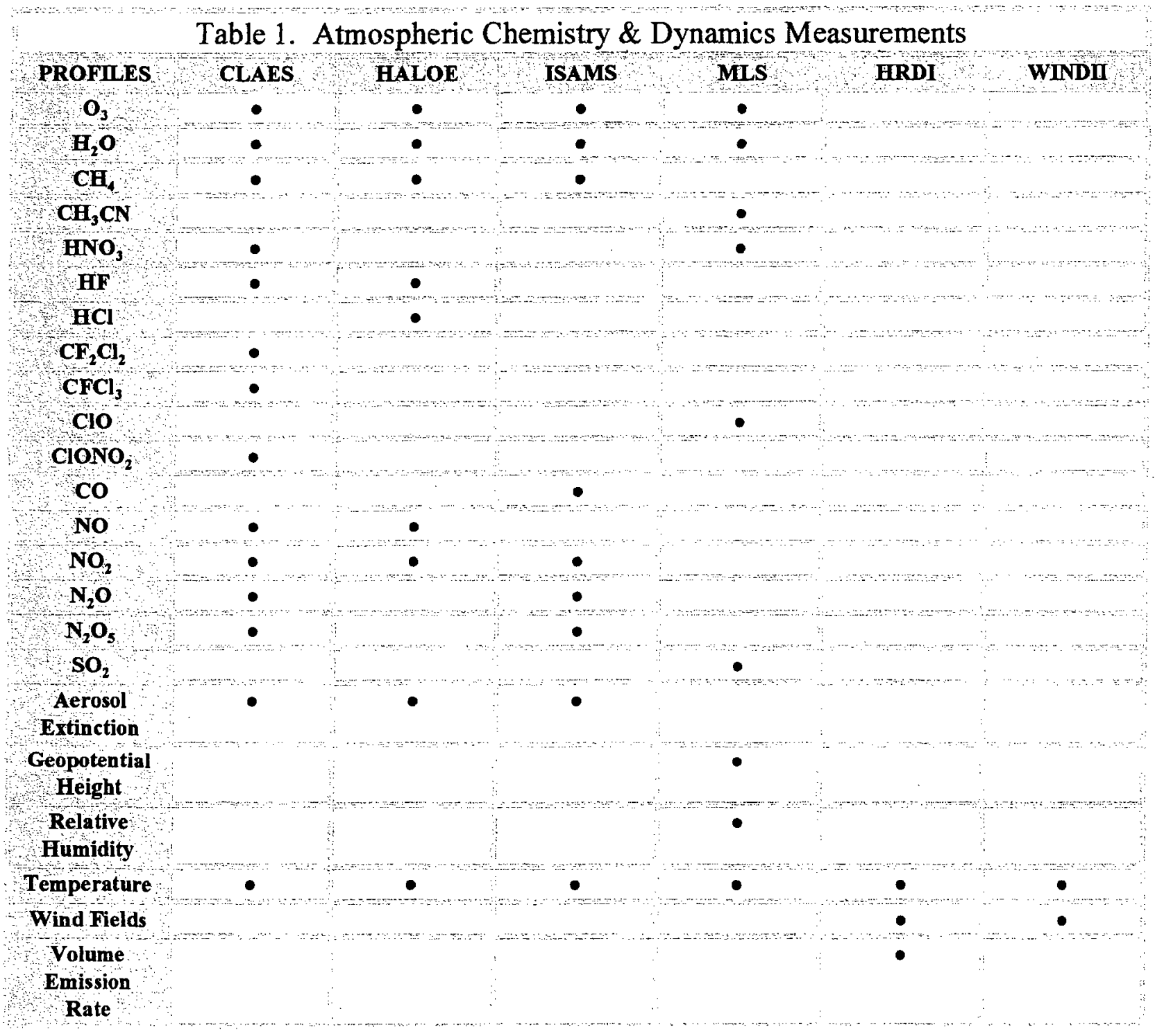

\section{UARS DATA PROCESSING \& DATA TYPES}

\section{UARS Processing}

The UARS data were processed from instrument activations beginning in September and October 1991 through September 2001 at the UARS Central Data Handling Facility (CDHF) located at NASA Goddard Space Flight Center (GSFC). UARS science data from different instruments are archived at GES Distributed Active Archive Center (DAAC) and publicly available from the GES DAAC. These UARS data and detailed data documents may 
be accessed from the GES DAAC website (http://daac.gsfc.nasa.gov). The UARS instrument team scientists released the data to the DAAC in stages pending completion of quality assurance procedures. Any additional measured atmospheric parameters from the UARS instruments that receive endorsement from the UARS Project Scientist in the future will also be archived at the GES DAAC, as they become available from the UARS science team.

Since October 2001 the UARS data have been processed at the individual instrument team locations. It should be noted that the file formats for UARS data archived in the Goddard DAAC are not the same VAX/VMS-based files obtained from the UARS CDHF. A translation tool has been used to convert from VMS keyed access with indexed organization to an IEEE sequential access with sequential organization and fixed length records.

The enhancement of data calibration and of science algorithms (for retrieving geophysical parameters from the measured and calibrated radiances and signals) is an ongoing effort. Over the years of the UARS mission many improvements have occurred and data were reprocessed producing an improved set of physical parameters and assigned a new version. These version numbers vary from sensor to sensor.

\section{Data Types}

The UARS data files are generated at five different processing levels:

Level 0: The basic telemetry data from the instruments after time reversal and decommutation into specific sensor files. Level 0 data have a common format.

Level 1: Calibrated measurements (e.g. counts converted to radiances) at original instrument spatial and temporal resolutions. Level 1 data have sensor specific file formats.

Level 2: Geophysical derived parameters (e.g. temperature profiles, gas concentrations, and winds) derived from the Level 1 data, at original instrument spatial ("footprint") and temporal resolutions. Level 2 data also have sensor specific file formats.

Level 3A: Geophysical derived parameters (Level 2 data) transformed into a common format and equally spaced along the measurement trajectory in

Time: "Level 3AT" (at 65.536 second centers and about a $500 \mathrm{~km}$ interval along orbital track), and associated auxiliary quality parameter files "Level 3TP". Level 3AT files are generated by the CLAES, HALOE, HRDI, ISAMS, MLS, PEM, and WINDII instruments. Level 3TP and 3AT files use the same format. However, PEM's level 3TP provide detailed energy deposition profiles of electron and proton at a higher temporal resolution, $2.048 \mathrm{sec}$ for data from High Energy Particle Spectrometer (HEPS) and 65.536 sec for data from Medium Energy Particle Spectrometer (MEPS), than the corresponding electron and proton level 3AT data products, which are only produced when there are simultaneous HEPS and MEPS measurements. Altitude coverage is the same as in the 3AT files.

Latitude: "Level 3AL" (at every four degrees latitude) and associated auxiliary quality parameter files "Level 3LP". The level 3AL data values are derived from the associated level 3AT data by interpolating to the nearest 4 degree latitude (about $440 \mathrm{~km}$ ) along the orbital track. The standard latitude values at which level $3 \mathrm{AL}$ records are written are from -88.0 degrees to +88.0 degrees latitude in 4.0 degree latitude increments along the orbital track. Level $3 \mathrm{AL}$ data are generated from UARS sensors (CLAES, ISAMS, MLS, HRDI and WINDII).

Level 3B: UARS level 3B data are generated from the level 3AL data. The technique is based upon sequential estimation using Kalman filtering, similar to that applied to the Nimbus 7 LIMS instrument data (Haggard et al., 1986). The estimator is run forward and backward in time for several days and the results combined to produce a $3 B$ product corresponding to 1200 GMT each day. In order to minimize the impact of local time variations on the results, the 3B data are derived separately for the ascending and descending portions of the orbits. Thus for each sensor and data species/subtype there are two separate files per day (one for north-going and other for south-going satellite data, which differ by 12 hours local time at the equator) at approximately one half scale height altitude intervals. These data are stored (in common file format) as 13 Fourier coefficients (one constant term, 6 coefficients for cosine terms, and 6 for sine terms) for each scale height altitude around the latitude circles defined by Level $3 \mathrm{AL}$. In addition to that another two files consisting of covariances (which provide estimates of the uncertainties inherent in the derived coefficients) are also generated separately (one for the ascending and other for the descending portions of the orbits). The following expression (Haggard et al., 1986) is used to relate the level 3B Fourier coefficients a to a geophysical quantity $x$ at any longitude $\varphi_{j}: x\left(\varphi_{j}\right)=a_{1}+\Sigma_{n=1}$ to $6\left\{a_{n} \cos n \varphi_{j}+a_{n+6} \sin n \varphi_{j}\right\}$ 
Not all the data are available in all the formats. Level 3B data are currently available for the five limb viewing UARS instruments (CLAES, ISAMS, MLS, HRDI, WINDII) for which level 3AL data files exist. There is no Level $3 \mathrm{AL}$ or Level $3 \mathrm{~B}$ file for the trace species profiles which are retrieved from the solar occultation measurement technique based sensor, HALOE.

Level $3 \mathrm{AL}$ products are also not available for the instruments that measure energy input into the atmosphere (i.e., SOLSTICE, SUSIM and PEM). For SOLSTICE and SUSIM data, Level 3B definitions differ from the other sensors. The file types are Level 3AS (based on calibration coefficient extrapolated from previous degradation coefficients) and Level 3BS (based on degradation coefficients applied from pre and post degradations measurements) and contain a single array representing a daily averaged solar spectrum for each spectral interval.

\begin{tabular}{|c|c|c|c|c|c|c|}
\hline & CLAES & HALOE & ISAMS & MLS & HRDI & WINDA \\
\hline $\begin{array}{l}\text { Spectral } \\
\text { Region }\end{array}$ & $\begin{array}{l}3.5 \text { to } 12.7 \\
\text { microns }\end{array}$ & $\begin{array}{l}2.43 \text { to } 10.25 \\
\text { micron }\end{array}$ & $\begin{array}{l}4.6 \text { to } 16.6 \\
\text { microns }\end{array}$ & $\begin{array}{c}63,183,205 \\
\mathrm{GHZ}\end{array}$ & $\begin{array}{c}0.557-0.775 \\
\text { micron }\end{array}$ & $\begin{array}{c}0.557-0.9 \\
\text { micron }\end{array}$ \\
\hline File Type & $3 \mathrm{AL}, 3 \mathrm{AT}, 3 \mathrm{~B}$ & $\begin{array}{c}\text { Level-2 \& } \\
3 A T\end{array}$ & $3 \mathrm{AL}, 3 \mathrm{AT}, 3 \mathrm{~B}$ & $3 \mathrm{AL}, 3 \mathrm{AT}, 3 \mathrm{~B}$ & $3 A L \& 3 A T$ & $3 \mathrm{AL} \& 3 \mathrm{AT}$ \\
\hline Data Version & 9 & 19 & 10 & $4 \& 3$ & 11 & 11 \\
\hline Data Period & Oct 91 - May 93 & Oct.91-Present & Sep 91-Jul 92 & Sept $91-\mathrm{Jul} 99^{*}$ & Nov 91-Present & Nov 91-Present \\
\hline
\end{tabular}

\section{Spatial \& Vertical Resolution of all Derived Products}

Spatial coverage is dependent on the instrument and ranges between 80 degrees south and 80 degrees north. Because of the 57 degree orbital inclination of the spacecraft, the orbit plane precesses at the rate of 5 degrees a day relative to the Sun, thus the limb sounders that view at 90 degree to the spacecraft velocity can "see" to 80 degrees in one hemisphere and 34 degrees in the other hemisphere providing data over all local times about every 36 days (Reber et al., 1993)

In general, the UARS spacecraft is rotated in yaw by 180 degrees on average about once every 36 days (termed a yaw cycle) in order to keep the solar panels pointing toward the sun and instruments away from the direct sun heat, thus periodically (10 times per year) alternating the hemisphere for maximum latitudinal coverage. The MLS, ISAMS, and CLAES instruments gather measurements between latitudes $80 \mathrm{~N}$ and $34 \mathrm{~S}$ in the forward (Northern Hemisphere pointing) mode, and between $80 \mathrm{~S}$ and $34 \mathrm{~N}$ in the aft (Southern Hemisphere pointing) mode. For the wind instruments, HRDI and WINDII, the nominal latitudinal coverage is between 74N and $60 \mathrm{~S}$ in the forward mode and between $74 \mathrm{~S}$ and $60 \mathrm{~N}$ in the backward mode. The latitudinal resolution of level $3 \mathrm{AL}$ (latitude referenced) is 4 degrees or about $440 \mathrm{~km}$ along orbital track, and $495 \mathrm{~km}$ for level $3 \mathrm{AT}$ (time referenced) data.

For level $3 \mathrm{~A}$ data vertical resolution is about $2.5 \mathrm{~km}$ for pressure referenced data arrays, and 3 to $5 \mathrm{~km}$ for altitude referenced data arrays. UARS trace gas profiles for level 3 CLAES, ISAMS and MLS data are reported at a set of up to 46 standard pressure levels (in millibars) defined by the UARS science team. WINDII level 3 profiles are reported at 88 UARS standard altitude $(\mathrm{km})$ grid also defined by the UARS science team. However, HRDI outputs are for both the pressure and altitude grids.

\begin{tabular}{|c|c|c|c|c|}
\hline & SOLSTICE & SUSIM & ACRIM II & PEM \\
\hline Spectral Region & 115 to $430 \mathrm{~nm}$ & 120 to $400 \mathrm{~nm}$ & $\begin{array}{l}\text { Total Solar } \\
\text { spectral region }\end{array}$ & Particles \& X-rays \\
\hline File Type & 3BS & $3 \mathrm{BS}$ & Level-2 \& 3AT & 3AT \& 3TP \\
\hline Data Version & 9 & 20 & & $4 \& 3$ \\
\hline Data Period & Oct 91-Present & Oct 91-Present & Sept 91 -Aug 01 & Oct 91-Present \\
\hline Parameters & UV irradiance & UV irradiance & Total Irradiance & $\begin{array}{l}\text { Electron, Proton, \& X-ray Energy } \\
\text { Deposition, and Magnetic Field }\end{array}$ \\
\hline
\end{tabular}

DATA ACCESS \& DATA SUPPORT AVAILABLE FROM NASA GES DAAC 
All standard UARS (Level 3 from all the sensors \& Level 2 from HALOE) products, consisting of measurements of atmospheric internal structure (trace constituents, physical dynamics, radiative emission, thermal structure, density) and measurements of the external influences acting upon the upper atmosphere (solar radiation and charged particle precipitation) and ancillary data consisting of model analyses and correlative measurements are archived at the NASA Goddard Earth Sciences (GES) DAAC. One of the main goals of the GES DAAC is making the data easily accessible to the wider user community. All of the data sets archived at GES DAAC are freely made available to the public and science user communities. These data sets may be accessed via several mechanisms including

-GES DAAC Search and Order

A user friendly Web-based search and order system, with full-features of spatial \& temporal search http://daac.gsfc.nasa.gov/data/

- EOS Data Gateway (EDG)

This interface provides access to satellite data that is available from all NASA data archive centers and NASA affiliated centers http://eos.nasa.gov/imswelcome/

\section{- Anonymous FTP Site}

A majority of the UARS and other related data sets are available from the GES DAAC anonymous FTP server ftp://daac.gsfc.nasa.gov/data/

\section{Read Software and Data Extraction Tools}

To facilitate the use of UARS data sets, a simple read/dump programs for all of the UARS data file types (including correlative data set) are available through the Goddard DAAC. Both FORTRAN \& $C$ versions of the read programs and compiled modules for all platforms (including Windows) are available for each data type. The Goddard DAAC has also created a shell script called "read_uars" (an interface with simple read/dump programs for all of the UARS data files) to allow the users to immediately view the data they have ordered.

\section{Other Long-term Atmospheric Chemistry, Dynamics, and Solar Irradiance Data Base at the GES DAAC}

The data from these future upper atmospheric research missions, e.g., the Ozone Monitoring Instrument (OMI) the Microwave Limb Sounder (MLS) and the High Resolution Dynamics Limb Sounder (HIRDLS) aboard Aura, as well as Solar Radiation and Climate Experiment (SORCE) will also be archived at the Goddard DAAC. Data products from several heritage atmospheric data missions including Nimbus-4 Backscatter Ultraviolet Spectrometer, Nimbus-7 Solar Backscatter Ultraviolet Spectrometer, a series of Total Ozone Mapping Spectrometer (TOMS) instruments, Television Infrared Observational Satellite (TIROS) Operational Vertical Sounder (TOVS) pathfinder, Data Assimilation Office (DAO) products are also archived at the Goddard DAAC. The continuity of the long-term solar UV measurements will be maintained with the launch of SORCE in early 2003 and the continuity of the longterm atmospheric chemistry, dynamics, and solar UV measurements will be maintained with the launch of the EOS Aura spacecraft in early 2004.

\section{REFERENCES}

Haggard, K.V., et. al., 1986, Description of Data on the Nimbus 7 LIMS Map Archive Tape, NASA Technical Paper 2553.

Jackman, C. H., and A. R. Douglass, Overview of the upper atmosphere research satellite: Observations from 1991 to 2002, COSPAR 2002, this issue.

Reber, C. A., C. E. Trevathan, R. J. McNeal, and M. R. Luther, The Upper Atmosphere Research Satellite (UARS) mission, J. Geophys. Res., 98, D6, 10643-10647, 1993.

Schoeberl, M. R., A. R. Douglass, and C. H. Jackman, Overview and highlights of the UARS mission, SPIE-The International Society for Optical Engineering, 2266, 254-265, 1994.

E-mail address of S. P. Ahmad: ahmadiadaac.gsfc.nasa.gov

Manuscript received 14 December 2002; revised xx December 2002; accepted 